\title{
Biopotential of Sea Cucumbers (Echinodermata) and Tunicates (Chordata) from the Western Coast of Portugal for the Prevention and Treatment of Chronic Illnesses ${ }^{+}$
}

\author{
Alessio Carletti 1,2, , Carlos Cardoso 3,4, , Diana Juliao ${ }^{3}$, Jorge L. Arteaga 5,6, Paula Chainho 7, \\ Maria Ana Dionísio ${ }^{7}$, Sabrina Sales ${ }^{3}$, Maria J. Gaudêncio ${ }^{5}$, Inês Ferreira ${ }^{3}$, Cláudia Afonso 3,4, \\ Helena Lourenço $^{3}$, M. Leonor Cancela ${ }^{1,2,8,9}$, Narcisa M. Bandarra ${ }^{3,4}$ and Paulo J. Gavaia ${ }^{1,2, *}$ \\ 1 Faculty of Biomedical Sciences and Medicine FCBM, University of Algarve, Campus de Gambelas, \\ 8005-139 Faro, Portugal; a.carletti91@gmail.com (A.C.); lcancela@ualg.pt (M.L.C.) \\ 2 Centre of Marine Sciences, University of Algarve, Campus de Gambelas, 8005-139 Faro, Portugal \\ 3 Division of Aquaculture, Upgrading and Bioprospection, Portuguese Institute for the Sea and Atmosphere, \\ IPMA, Avenida Alfredo Magalhães Ramalho, 6, 1495-165 Algés, Portugal; carlos.cardoso@ipma.pt (C.C.); \\ dr.juliao@campus.fct.unl.pt (D.J.); sabrinadesouzasales@gmail.com (S.S.); is.ferreira@campus.fct.unl.pt \\ (I.F.); cafonso@ipma.pt (C.A.); narcisa@ipma.pt (N.M.B.) \\ 4 Interdisciplinary Centre of Marine and Environmental Research (CIIMAR/CIMAR), University of Porto, \\ Rua dos Bragas 289, 4050-123 Porto, Portugal \\ 5 Division of Environmental Oceanography, Portuguese Institute for the Sea and Atmosphere, IPMA, \\ Avenida Alfredo Magalhães Ramalho, 6, 1495-165 Algés, Portugal; j.loboarteaga@gmail.com (J.L.A.); \\ mgaudencio@ipma.pt (M.J.G.) \\ 6 Marine and Environmental Sciences Centre (MARE), NOVA University of Lisbon, \\ 2829-516 Caparica, Portugal \\ 7 Faculty of Science, University of Lisbon, Campo Grande, 1749-016 Lisbon, Portugal; \\ pmchainho@fc.ul.pt (P.C.); \\ 8 Algarve Biomedical Center ABC, University of Algarve, Campus de Gambelas, 8005-139 Faro, Portugal \\ 9 Centre for Biomedical Sciences CBMR, University of Algarve, Campus de Gambelas, \\ 8005-139 Faro, Portugal \\ * Correspondence: pgavaia@ualg.pt \\ + Presented at the The 1st International Electronic Conference on Nutrients - Nutritional and Microbiota \\ Effects on Chronic Disease, 2-15 November 2020; Available online: https://iecn2020.sciforum.net/. \\ $\ddagger$ Both authors contributed equally.
}

Published: 30 October 2020

\begin{abstract}
In the present work we aimed at exploring the potential of two group of marine invertebrates-sea cucumbers (Echinodermata) and ascidians (Chordata) as sources of antiInflammatory, anti-oxidant and osteogenic compounds with potential to be used as pharmaceuticals and nutraceuticals for the treatment and prevention of chronic diseases. 24 extracts (ethanol, water \& ethyl acetate) from 4 species of sea cucumbers and 4 species of tunicates, were produced and screened in vitro for their anti-inflammatory, antioxidant activities and in vivo for osteogenic activity through an assay using zebrafish larvae. Our results showed that ethanolic extracts presented antioxidant and anti-inflammatory activity, which revealed to be stronger in the ascidians. The osteogenic activity, that provide evidences of the bioactive potential of these organisms in preventing chronic disorders causing low bone density, was found to be strong in one species of ascidians and 3 of holothurians. This study evidences the high potential of extracts from these marine organisms for using as nutraceuticals in the prevention of chronic bone disorders.
\end{abstract}


Keywords: chronic diseases; nutraceuticals; natural compounds; sea cucumbers; tunicates; antiinflammatory; anti-oxidants; osteogenic

\section{Introduction}

Chronic diseases are a major cause of death and morbidity globally [1]. Among these, osteoporosis and osteopenia, are the most common chronic disorders related to bone [2]. Although much remains unclear about the molecular mechanism underlying the development of chronic diseases, a growing body of evidences has stressed the importance of inflammation and oxidative stress. In this context, nutraceuticals and functional foods promise to be important sources of micronutrients, antioxidants and anti-inflammatory compounds for the prevention of chronic diseases [3]. The marine environment is considered a potentially inexhaustible source of bioactive compounds. Sea cucumbers (Holothuroidea) and ascidians (Ascidiacea) have gained the attention of the pharmaceutical sector due to the large amount of bioactives isolated from these groups of marine invertebrates, which have been associated with anti-inflammatory, antioxidant and osteogenic activities, among others [4,5]. In the present work, we evaluated the bioactivity of extracts produced from 4 species of sea cucumbers belonging to the Family Holothuriidae and 4 species of ascidians, belonging to the Families Styelidae and Polyclinidae. Our aim was to explore the bioactive potential of these species for applications in the prevention and treatment of bone related chronic disorders. Anti-inflammatory activity, antioxidant potential and polyphenol content were assessed for the aqueous and ethanolic extracts obtained from sea cucumbers and ascidians. Further, in order to evaluate the potential of these species, all the extracts were screened for their pro-osteogenic bioactivity within a recently developed zebrafish based in vivo system.

\section{Materials and Methods}

Ethanol, water and ethyl acetate extracts were produced from 4 species of sea cucumbers belonging to the Family Holothuriidae (Holothuriidae ni1, Holothuriidae ni2, Holothuriidae ni3, Holothuriidae ni4) and 4 species of ascidians, 1 from the Family Styelidae (Styelidae ni1) and 3 from the Family Polyclinidae (Polyclinidae ni1, Polyclinidae ni2 and Polyclinidae ni3), collected from the western coast of Portugal.

\subsection{Preparation of the Extracts}

A total of 24 extracts were obtained by solvent extraction from sea cucumbers and ascidians freeze-dried biomass. The biomass was ground into fine powder and solubilized in water, ethanol or ethyl acetate with a ratio 1:30 w/v. Solutions were homogenized and left for $16 \mathrm{~h}$ to extract soluble compounds. Extracts were centrifuged to remove insoluble material and aliquoted.

\subsection{Antioxidant Activity and Polyphenol Content}

Antioxidant potential was assessed for the ethanolic and aqueous extracts. Free radical scavenging capacity was assessed through FRAP, ABTS+ and DPPH methods [6,7]. The polyphenol content was determined in the aqueous and ethanolic extracts by colorimetric determination with phosphomolybdic-phosphotungstic acid, using a protocol adapted from Singleton et el. (1965) [8].

\subsection{Anti-Inflammatory Activity}

Anti-inflammatory activity was evaluated by cyclooxygenase inhibitory assay, an established biomarker of inflammation processes [9].

\subsection{Developmental Toxicity and Osteogenic Activity in Zebrafish Larvae}

Aqueous, ethanolic and ethyl acetate extracts from sea cucumbers and ascidians were screened for their acute developmental toxicity in a $72 \mathrm{~h}$ exposure of zebrafish larvae. At 3 days post fertilization larvae 
were transferred to 6 well-plates with a density of 15 larvae per $10 \mathrm{~mL}$ of treatment medium/well. The larvae were treated via waterborne exposure for $72 \mathrm{~h}$ with different concentrations of each extract and their respective solvents as control groups $(0.1 \% v / v$ ethanol for ethanol extracts, fish water for aqueous extracts; and $0.1 \% v / v$ DMSO for ethyl acetate extracts). Treatment medium was renewed daily (70\%). All the extracts were first tested at a concentration of $100 \mu \mathrm{g} / \mathrm{mL}$ and toxicity was monitored during 3 days of exposure. Mortality and severe deformation were considered as endpoints for toxicity. When the treatments resulted toxic, the dose was reduced to 10 or $31.6 \mu \mathrm{g} / \mathrm{mL}$ and the experimental exposure repeated. If no toxicity was observed, the dose was increased to $200 \mu \mathrm{g} / \mathrm{mL}$. The maximum non-lethal dose (MNLD) was selected to evaluate the osteogenic activity with the zebrafish operculum assay, an in vivo, phenotypic-based method that uses morphometric analysis of the opercular bone in alizarin red $\mathrm{S}$ stained zebrafish larvae [10]. The area of the operculum $(O p A)$ and the area of the head $(H A)$ were measured and used to determine osteogenic activity.

\section{Results and Discussion}

\subsection{Anti-Inflammatory Activity}

The anti-inflammatory activity in the biomass of the eight species of marine organisms was measured as the percentage of inhibition of COX-2 (Table 1). The ethanolic extracts showed higher antiinflammatory activity than the aqueous extracts, and the higher activity was reported for the ascidians.

Table 1. Anti-inflammatory activity (\% inhibition of COX-2) in aqueous and ethanolic extracts from 4 ascidian and 4 sea cucumber species. Values are presented as average \pm SD. Different lowercase letters within a column correspond to statistical differences $(p<0.05)$ between organism species. Different uppercase letters within a row correspond to statistical differences $(p<0.05)$ between aqueous and ethanolic extracts. nd - not detected.

\begin{tabular}{|c|c|c|}
\hline \multirow{2}{*}{ Species } & \multicolumn{2}{|c|}{ Anti-Inflammatory Activity } \\
\hline & Aqueous Extract & Ethanolic Extract \\
\hline Styelidae ni1 & $19.6 \pm 5.8 \mathrm{c}, \mathrm{A}$ & $76.7 \pm 3.4^{c, B}$ \\
\hline Polyclinidae ni1 & $27.8 \pm 2.5 \mathrm{~d}, \mathrm{~A}$ & $70.2 \pm 6.3 \mathrm{c}, \mathrm{B}$ \\
\hline Polyclinidae ni2 & $8.9 \pm 3.7 \mathrm{~b}, \mathrm{~A}$ & $75.9 \pm 3.0 \mathrm{c}, \mathrm{B}$ \\
\hline Polyclinidae ni3 & $33.2 \pm 5.2 \mathrm{~d}, \mathrm{~A}$ & $92.2 \pm 8.5^{\mathrm{d}, \mathrm{B}}$ \\
\hline Holothuriidae ni3 & nd a,A & $40.0 \pm 7.6^{b, B}$ \\
\hline Holothuriidae ni4 & nd $\mathrm{a}, \mathrm{A}$ & $41.8 \pm 4.9 \mathrm{~b}, \mathrm{~B}$ \\
\hline Holothuriidae ni2 & nd $\mathrm{a}^{\mathrm{a}} \mathrm{A}$ & $48.8 \pm 3.4^{\mathrm{b}, \mathrm{B}}$ \\
\hline Holothuriidae ni1 & nd a, A & $16.4 \pm 9.7 \mathrm{a}, \mathrm{B}$ \\
\hline
\end{tabular}

\subsection{Antioxidant Activity and Polyphenol Content}

The antioxidant activity and polyphenol content are presented in Table 2 . The set of three tunicate species belonging to the Family Polyclinidae displayed the highest antioxidant activities in both extracts, with the only remarkable exceptions of the aqueous extracts of Polyclinidae ni1 and Polyclinidae ni2 with their antioxidant power measured by DPPH. With respect to te antioxidant activities of the holothurians, these were generally lower than in the ascidians. The ethanolic extracts from the ascidians were also generally richer in polyphenols than the aqueous extracts and tunicates had higher polyphenol content compared with holothurians. Total polyphenol contents had a weak correlation with the antioxidant activity even in the best case, that is DPPH $\left(R^{2}=0.29\right)$. It should be noted that there are other antioxidant substances in tunicates [11] and sea cucumbers [12] which may be responsible for the effect reported. Comparisons with the relevant literature must consider used methodologies, measurement units, and type of extract. Further research on the seasonality and overall variation of phenolic substances and antioxidant activity in tunicates and holothurians is required. 
Table 2. Antioxidant activity as measured by ABTS ( $\mu$ mol eq TROLOX/100 g dw), FRAP ( $\mu$ mol eq FeSO $4 / g$ dw), and DPPH (mg eq AA/100 g dw) and polyphenol content $(\mathrm{mg} \mathrm{GAE} / 100 \mathrm{~g} \mathrm{dw})$ in aqueous and ethanolic extracts. Values presented as average \pm SD. For antioxidant activity, different lowercase letters within a column correspond to statistical differences $(p<0.05)$ between organism species. For each antioxidant method, different uppercase letters within a row correspond to statistical differences $(p$ $<0.05)$ between aqueous and ethanolic extracts. Within the polyphenol's column, different uppercase letters between aqueous and ethanolic extracts correspond to statistical differences $(p<0.05)$ between the extract types. nd - not detected.

\begin{tabular}{|c|c|c|c|c|c|c|c|c|}
\hline \multirow[t]{2}{*}{ Species } & \multicolumn{2}{|c|}{$\begin{array}{l}\text { ABTS } \\
\text { Extract }\end{array}$} & \multicolumn{2}{|c|}{$\begin{array}{l}\text { FRAP } \\
\text { Extract }\end{array}$} & \multicolumn{2}{|c|}{$\begin{array}{l}\text { DPPH } \\
\text { Extract }\end{array}$} & \multicolumn{2}{|c|}{$\begin{array}{c}\text { Polyphenols } \\
\text { Extract }\end{array}$} \\
\hline & Aqueous & Ethanolic & Aqueous & Ethanolic & Aqueous & Ethanolic & Aqueous & Ethanolic \\
\hline Styelidae ni1 & $1126 \pm 81^{\mathrm{a}, \mathrm{A}}$ & $552 \pm 60$ b,B & $2.9 \pm 0.5 \mathrm{a}, \mathrm{A}$ & $5.5 \pm 0.1 \mathrm{~b}, \mathrm{~B}$ & $6.9 \pm 10.9 \mathrm{a}, \mathrm{b}, \mathrm{A}$ & $\mathrm{nd}^{\mathrm{a}, \mathrm{B}}$ & $31 \pm 6^{a, A}$ & $40 \pm 7 \mathrm{~b}, \mathrm{~A}$ \\
\hline Polyclinidae ni1 & $6206 \pm 180 \mathrm{f}, \mathrm{A}$ & $5020 \pm 20 \mathrm{~d}, \mathrm{~B}$ & $34.3 \pm 0.4^{\mathrm{e}, \mathrm{A}}$ & $34.2 \pm 0.1 \mathrm{~d}, \mathrm{~A}$ & nd $\mathrm{a}, \mathrm{A}$ & $102.0 \pm 1.6^{\mathrm{b}, \mathrm{B}}$ & $260 \pm 13 \mathrm{~d}, \mathrm{~A}$ & $365 \pm 21 \mathrm{~d}, \mathrm{~B}$ \\
\hline Polyclinidae ni2 & $6735 \pm 11 \mathrm{~g} A$ & $5886 \pm 83$ e,B & $54.6 \pm 0.4 \mathrm{f}, \mathrm{A}$ & $56.5 \pm 0.0$ e,B & $16.7 \pm 4.1^{\mathrm{b}, \mathrm{c}, \mathrm{A}}$ & $179.0 \pm 1.7 \mathrm{c}, \mathrm{B}$ & $428 \pm 10 \mathrm{e}, \mathrm{A}$ & $669 \pm 11$ e,B \\
\hline Polyclinidae ni3 & $4271 \pm 109 \mathrm{e}, \mathrm{A}$ & $3027 \pm 56$ c,B & $19.7 \pm 0.6 \mathrm{~d}, \mathrm{~A}$ & $15.6 \pm 0.6 \mathrm{c}, \mathrm{B}$ & $151.7 \pm 4.4 \mathrm{e}, \mathrm{A}$ & $162.7 \pm 2.5 \mathrm{c} B \mathrm{~B}$ & $103 \pm 8 \mathrm{c}, \mathrm{A}$ & $206 \pm 14$ c,B \\
\hline Holothuriidae ni3 & $2234 \pm 136$ c,A & $166 \pm 35 \mathrm{a}, \mathrm{B}$ & $7.0 \pm 0.2 \mathrm{~b}, \mathrm{~A}$ & $2.0 \pm 0.1 \mathrm{a}, \mathrm{B}$ & nd $\mathrm{a}, \mathrm{A}$ & $13.5 \pm 12.7 \mathrm{a}, \mathrm{B}$ & $84 \pm 4$ b,c,A & $9 \pm 5 a, b, b$ \\
\hline Holothuriidae ni4 & $3089 \pm 158 \mathrm{~d}, \mathrm{~A}$ & $33 \pm 57 \mathrm{a}, \mathrm{B}$ & $6.2 \pm 0.0^{\mathrm{b}, \mathrm{A}}$ & $1.5 \pm 0.2 \mathrm{a}, \mathrm{B}$ & $31.8 \pm 6.2 \mathrm{c}, \mathrm{A}$ & $5.7 \pm 9.8^{a, b}$ & $79 \pm 1 \mathrm{~b}, \mathrm{~A}$ & $21 \pm 17 \mathrm{a}, \mathrm{b}, \mathrm{B}$ \\
\hline Holothuriidae ni2 & $2259 \pm 45 \mathrm{c}, \mathrm{A}$ & $312 \pm 320$ a,b,b & $8.5 \pm 0.2 \mathrm{c}, \mathrm{A}$ & $4.4 \pm 1.5^{\mathrm{b}, \mathrm{B}}$ & $3.0 \pm 5.1^{\mathrm{a}, \mathrm{b}, \mathrm{A}}$ & $8.6 \pm 8.5 \mathrm{a}, \mathrm{A}$ & $69 \pm 2 b, A$ & $34 \pm 11^{\mathrm{a}, \mathrm{b}, \mathrm{B}}$ \\
\hline Holothuriidae ni1 & $1883 \pm 81 \mathrm{~b}, \mathrm{~A}$ & nd $\mathrm{a}, \mathrm{B}$ & $8.9 \pm 0.5 \mathrm{c}, \mathrm{A}$ & $2.1 \pm 0.6 \mathrm{a}, \mathrm{B}$ & $106.1 \pm 4.7 \mathrm{~d}, \mathrm{~A}$ & nd $\mathrm{a}, \mathrm{B}$ & $48 \pm 2 \mathrm{a}, \mathrm{A}$ & nd $\mathrm{a}, \mathrm{B}$ \\
\hline
\end{tabular}




\subsection{Developmental Toxicity and Osteogenic Activity}

Acute developmental toxicity was calculated for the ethanolic, aqueous and ethyl acetate extracts from 4 species of sea cucumbers (Holothuriidae ni1, Holothuriidae ni2, Holothuriidae ni3, Holothuriidae ni4) and 4 species of ascidians (Styelidae ni1, Polyclinidae ni1, Polyclinidae ni2 and Polyclinidae ni3). Most of the aqueous and ethanolic extracts showed no toxicity at the concentrations tested, except for the ethanol extracts of Holothuriidae ni1 that induced mortality at the higher concentration $(200 \mu \mathrm{g} / \mathrm{mL})$. Oppositely, all the ethyl acetate extracts induced severe mortality at the higher concentration tested $(100 \mu \mathrm{g} / \mathrm{mL})$, indicating the possible presence of toxic compounds in the extracts. The MNLD determined for each extract was then used to assess the osteogenic activity. Control groups did not show mortality in any of the assays performed. The area of the operculum $(O p A)$ and the area of the head $(H A)$ were measured and the ratio $O p A / H A$ was calculated for assessing osteogenic activity (Figure 1). None of the extracts significantly affected the area of the head $(H A)$, a proxy of the size of the larva, indicating there was no significant variation on growth among treatments. The ethyl acetate extracts of the ascidian Styelidae ni1 showed anti-osteogenic effects when compared with the control group. This indicates that osteotoxic or osteoblastic inhibitor compounds may be present in the extract. The ethanol extract from Styelidae ni1 and Polyclinidae ni3 induced moderate to high osteogenic activity by increasing the area of the operculum, when compared with the control. The ethanol extract from Polyclinidae ni1 showed the highest osteogenic activity by inducing an increase in the size of the opercular bone of $41 \pm 16.66 \%$ relatively to the control group. The ethyl acetate extracts of Polyclinidae ni1 induced the highest osteogenic effect among the ethyl acetate extracts, with an increase of the operculum area of $28.0 \pm 13.84 \%$. Regarding sea cucumbers, treatment with the ethanol extracts from Holothuriidae ni2, Holothuriidae ni3 and Holothuriidae ni4 showed a moderate osteogenic effect. This suggests the presence of osteogenic compounds in the extracts, with higher osteogenic power in the ethanolic extracts of the ascidians (Styelidae ni1, Polyclinidae ni1 and Polyclinidae ni3).
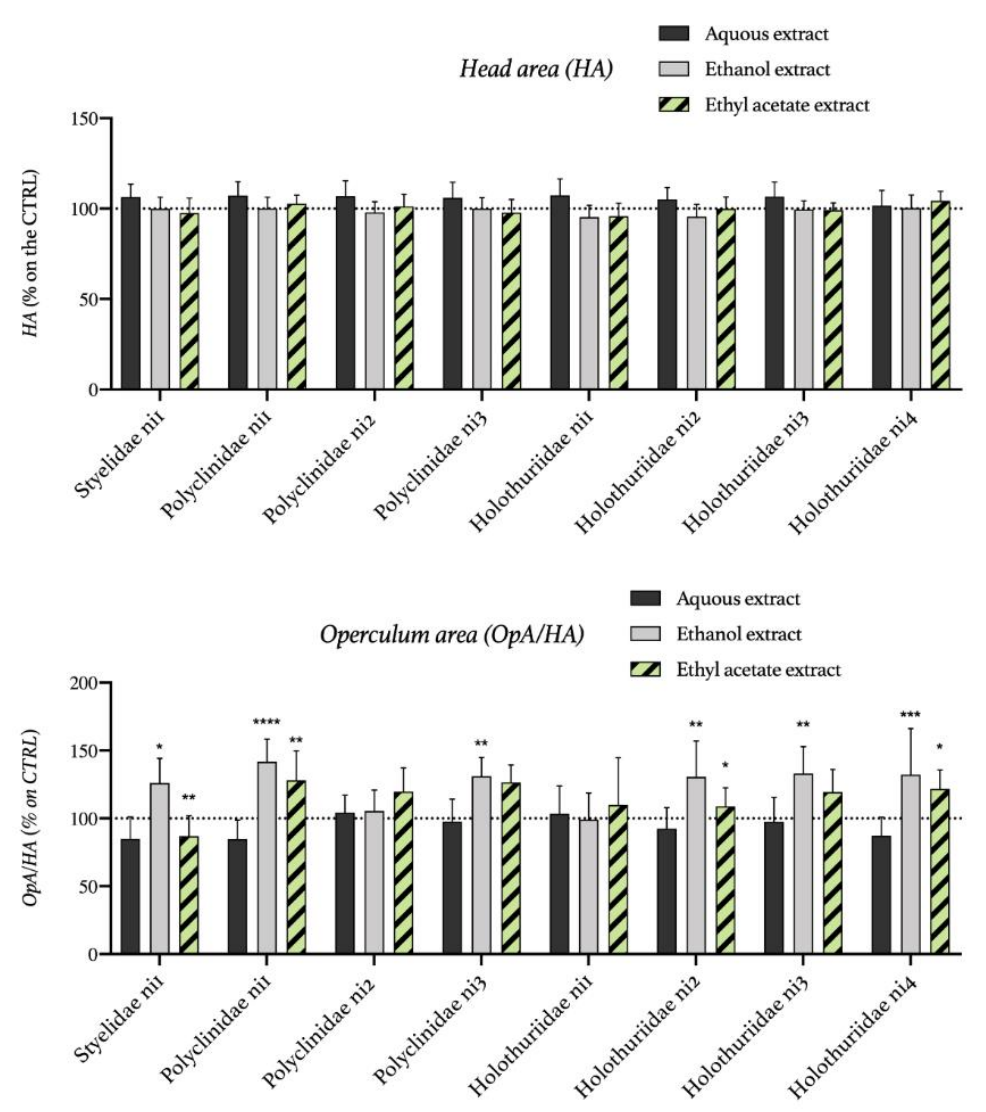
Figure 1. Osteogenic activity of water, ethanol and ethyl acetate extracts from sea cucumbers and ascidians in zebrafish larvae. Both $H A$ and $O p A / H A$ are reported as percentage on the average of the control group (water, ethanol $0.1 \% v / v$ or DMSO $0.1 \% v / v$ respectively). The averages $H A$ and $O p A / H A$ of the control group for each extract tested is represented by the axis $y=100(\%)$. Statistical differences among the means are tested through One-way ANOVA (between control and each condition). $p$ values are indicated as follow: $<0.0332\left({ }^{*}\right),<0.0021\left(^{* *}\right),<0.0002\left({ }^{* * *}\right),<0.0001\left(^{* * * *}\right)$.

Despite a large number of bioactive compounds was isolated from sea cucumbers and ascidians, the number of studies analyzing their potential for bone health is low and only based on in vitro studies.

Fucoidans derived from the holothurian Stichopus japonicus inhibited the differentiation of rat bone marrow macrophages into osteoclasts [13], similarly to what was observed for fucoidan extracted from brown seaweeds [14]. Furthermore, water and methanolic extracts from different species of sea cucumbers were found to be able to induce differentiation in human osteoblast cell lines [15] and rat bone marrow mesenchymal stem cells [16]. Very few studies analyzed the osteoactive properties of compounds derived from ascidians. Calcitonin-like peptides isolated from the sea squirt Ciona intestinalis showed to be able to promote osteoblastic differentiation and mineralization in MC3T3-E1 cells [17]. Aplidin, a compound isolated from the ascidian Aplidium albicans, known for its anticancer potential, was able to reduce osteoclast differentiation when administered both alone or together with dexamethasone in both murine bone marrow primary cell culture and in an ex vivo bone organ culture model [18].

Interestingly, in the present study a significant correlation was found between the osteogenic activity and the COX-2-inhibitory activity for the extracts studied $\left(\mathrm{R}^{2}=0.49\right)$. However, to understand the mechanisms underlying the biological activities observed, further investigation is needed to identify the compounds responsible for the effect observed in the extracts, as well as to understand the molecular pathways involved.

\section{Conclusions}

In the present work we explored the potential of two promising groups of marine invertebrates as sources of bioactive compounds to be used toward the prevention and treatment of low bone density chronic diseases. The ethanolic extracts from ascidians showed the higher antioxidant and anti-inflammatory activities, while ethanolic extracts from two ascidians and two sea cucumbers showed high in vivo osteogenic activity by promoting bone formation in zebrafish larvae. These findings indicate that ethanolic extracts from both ascidians and sea cucumber are potential sources of compounds with health benefits and require further research for chemical characterization of the extracts and identification of the compounds responsible for the effect reported.

Author Contributions: Conceptualization, A.C., C.C., L.C., N.B., P.J.G.; formal analysis, A.C., C.C., L.C., N.B., P.J.G.; investigation, A.C., C.C., L.C., N.B., P.J.G.; resources, C.C., L.C., N.B., P.J.G., M.J.G.; data curation, A.C., C.C., D.J., J.L.A., P.C., M.A.D., S.S., I.F., C.A.; writing - original draft preparation, A.C., C.C., P.J.G.; writingreview and editing, A.C., C.C., N.B., P.J.G., J.L.A., S.S.; supervision, C.C., N.B., M.J.G., L.C., P.J.G.; project administration, C.C., N.B., L.C., P.J.G.; funding acquisition, N.B., L.C., P.J.G. All authors have read and agreed to the published version of the manuscript.

Funding: This project received funding from the European Union's Horizon 2020 research and innovation programme under the Marie Skłodowska-Curie grant agreement No. 766347; and from the Portuguese national funds from FCT - Foundation for Science and Technology through project UIDB/04326/2020.

Conflicts of Interest: The authors declare no conflict of interest.

\section{References}

1. Damasceno, A. Noncommunicable Diseases Country Profiles 2018; World Health Organization: Geneva, Switzerland, 2018.

2. Reginster, J.-Y.; Burlet, N. Osteoporosis: A still increasing prevalence. Bone 2006, 38 (Suppl. 1), 4-9, doi:10.1016/j.bone.2005.11.024. 
3. Bergamin, A.; Mantzioris, E.; Cross, G.; Deo, P.; Garg, S.; Hill, A.M. Nutraceuticals: Reviewing their Role in Chronic Disease Prevention and Management. Pharm. Med. 2019, 33, 291-309, doi:10.1007/s40290-01900289-w.

4. Khotimchenko, Y. Pharmacological Potential of Sea Cucumbers. Int. J. Mol. Sci. 2018, 19, 1342, doi:10.3390/ijms19051342.

5. Blunt, J.W.; Copp, B.R.; Keyzers, R.A.; Munro, M.H.G.; Prinsep, M.R. Marine natural products. Nat. Prod. Rep. 2017, 34, 235-294.

6. Rodríguez-Bonilla, P.; Gandía-Herrero, F.; Matencio, A.; García-Carmona, F.; López-Nicolás, J.M. Comparative Study of the Antioxidant Capacity of Four Stilbenes Using ORAC, ABTS+, and FRAP Techniques. Food Anal. Methods 2017, 10, 2994-3000, doi:10.1007/s12161-017-0871-9.

7. Kedare, S.B.; Singh, R.P. Genesis and development of DPPH method of antioxidant assay. J. Food Sci. Technol. 2011, 48, 412-422, doi:10.1007/s13197-011-0251-1.

8. Singleton, V.L.; Rossi, J.A., Jr. Colorimetry of Total Phenolics With Phosphomolybdic-Phosphotungstic Acid Reagents. Am. J. Enol. Vitic. 1965, 16, 144-158.

9. White, H.L.; Glassman, A.T. A simple radiochemical assay for prostaglandin synthetase. Prostaglandins 1974, 7, 123-129, doi:10.1016/0090-6980(74)90131-2.

10. Tarasco, M.; Laizé, V.; Cardeira, J.; Cancela, M.L.; Gavaia, P.J. The zebrafish operculum: A powerful system to assess osteogenic bioactivities of molecules with pharmacological and toxicological relevance. Comp. Biochem. Physiol. Part C Toxicol. Pharmacol. 2017, 197, 45-52, doi:10.1016/j.cbpc.2017.04.006.

11. Zhang, X.; Liu, L.; Sun, M.; Chen, B.; Jiang, A. Preparation, chemical characterization and antioxidant activity of crude polysaccharide and oligosaccharide extracted from the ascidian Styela clava. J. Biotech Res. 2018, 9, 39-47.

12. Nobsathian, S.; Tuchinda, P.; Sobhon, P.; Tinikul, Y.; Poljaroen, J.; Tinikul, R.; Sroyraya, M.; Poomton, T.; Chaichotranunt, S. An antioxidant activity of the whole body of Holothuria scabra. Chem. Biol. Technol. Agric. 2017, 4, 17-21, doi:10.1186/s40538-017-0087-7.

13. Kariya, Y.; Mulloy, B.; Imai, K.; Tominaga, A.; Kaneko, T.; Asari, A.; Suzuki, K.; Masuda, H.; Kyogashima, M.; Ishii, T. Isolation and partial characterization of fucan sulfates from the body wall of sea cucumber Stichopus japonicus and their ability to inhibit osteoclastogenesis. Carbohydr. Res. 2004, 339, 1339-1346, doi:10.1016/j.carres.2004.02.025.

14. Kim, Y.W.; Baek, S.-H.; Lee, S.-H.; Kim, T.-H.; Kim, S.-Y. Fucoidan, a Sulfated Polysaccharide, Inhibits Osteoclast Differentiation and Function by Modulating RANKL Signaling. Int. J. Mol. Sci. 2014, 15, 1884018855, doi:10.3390/ijms151018840.

15. Shahrulazua, A.; Samsudin, A.; Iskandar, M.; Amran, A. The In-Vitro Effects of Sea Cucumber (Stichopus sp1) Extract on Human Osteoblast Cell Line. Malays. Orthop. J. 2013, 7, 41-48, doi:10.5704/MOJ.1303.015.

16. Baharara, J.; Amini, E.; Kerachian, M.A.; Soltani, M. The osteogenic differentiation stimulating activity of Sea cucumber methanolic crude extraction on rat bone marrow mesenchymal stem cells. Iran. J. Basic Med. Sci. 2014, 17, 626-631.

17. Nguyen, V.-T.; Ko, S.-C.; Heo, S.-J.; Kang, D.H.; Oh, C.; Kim, K.-N.; Jeon, Y.-J.; Kim, Y.-M.; Park, W.S.; Choi, I.-W.; et al. Ciona intestinalis calcitonin-like peptide promotes osteoblast differentiation and mineralization through MAPK pathway in MC3T3-E1 cells. Process Biochem. 2018, 67, 127-138, doi:10.1016/j.procbio.2018.01.025.

18. Delgado-Calle, J.; Kurihara, N.; Atkinson, E.G.; Nelson, J.; Miyagawa, K.; Galmarini, C.M.; Roodman, G.D.; Bellido, T. Aplidin (plitidepsin) is a novel anti-myeloma agent with potent anti-resorptive activity mediated by direct effects on osteoclasts. Oncotarget 2019, 10, 2709-2721, doi:10.18632/oncotarget.26831.

Publisher's Note: MDPI stays neutral with regard to jurisdictional claims in published maps and institutional affiliations.

(C) 2020 by the authors. Submitted for possible open access publication under the terms and conditions of the Creative Commons Attribution (CC BY) license (http://creativecommons.org/licenses/by/4.0/). 